\section{Oncologia Endócrina: da Pesquisa à Clínica Um Novo/Antigo Cenávio de Atuação do Endocrinologista}

$\mathrm{U}$ Ma Significativa Parcela de atuaÇão da Endocrinologia, tanto na pesquisa básica assim como na pesquisa clínica e assistência aos pacientes, envolve o diagnóstico e manejo de doenças neoplásicas. As neoplasias endócrinas foram inicialmente descritas a partir da observação arguta das manifestações clínicas e da possível associação com os distúrbios de hiper ou hipossecreção endócrina. Atualmente, ocorreram avanços importantes na medida dos hormônios séricos, permitindo o diagnóstico de alterações muito pequenas da sua produção, assim como foi possível identificar, em muitos casos, os mecanismos genéticos e moleculares responsáveis pelo aparecimento das neoplasias endócrinas.

No Brasil, um grande de número de serviços e pesquisadores vem contribuindo para um melhor entendimento de diversos aspectos da "Oncologia Endócrina", através da produção contínua de conhecimento, qualificando sobremaneira $\mathrm{o}$ atendimento dos pacientes portadores destes distúrbios.

Apesar destes envolvimentos históricos, assistenciais e de pesquisa, nosso sistema de saúde não valoriza ainda o papel do médico endocrinologista no manejo do câncer com repercussão endócrina. O Ministério da Saúde brasileiro, já há algum tempo, de uma forma bastante avançada e qualificada, organizou a assistência aos pacientes com câncer, estabelecendo rotinas para a realização de procedimentos e terapêuticas. Assim, foram criadas rotinas e autorizações (por exemplo, Autorização para Procedimentos de Alto Custo - APAC) que só podem ser realizadas a partir de um cadastro nacional que é de exclusividade de determinadas especialidades médicas como a Oncologia, a Radioterapia e a Medicina Nuclear. Neste ambiente, um médico endocrinologista treinado e muitas vezes com larga experiência no diagnóstico e manejo do câncer endócrino, com publicações internacionais a respeito, não pode solicitar, executar e prescrever medicamentos e/ou procedimentos no Sistema Único de Saúde brasileiro. Situação semelhante ocorre nos convênios e em algumas instituições, que também limitam a atuação do especialista em endocrinologia.

No momento em que nossa Sociedade vem desenvolvendo o projeto de Diretrizes Terapêuticas nacionais, sendo uma das áreas do conhecimento médico com maior atuação embasada em evidências, somos da opinião de que devemos também resgatar formal e oficialmente nossas atividades, direitos e deveres junto aos diversos sistemas assistenciais. Esta edição dos Arquivos pretende contribuir para esta discussão, demonstrando a qualificação relacionada ao tema encontrada entre os endocrinologistas brasileiros.

Há mais de um ano, diante da riqueza de informações que surgem em cada congresso e da extensa experiência de diversos Serviços brasileiros na área de oncologia, levamos ao nosso Editor-Chefe, Dr. Claudio Kater, a possibilidade de contribuirmos com a edição de um volume especial. Essa "Edição Especial" reuniria diversos temas relacionados ao câncer envolvendo as glândulas endócrinas e as principais repercussões hormonais asso-

\section{editorial}

\author{
Mauro A. Czepielewski \\ Jorge L. Gross
}

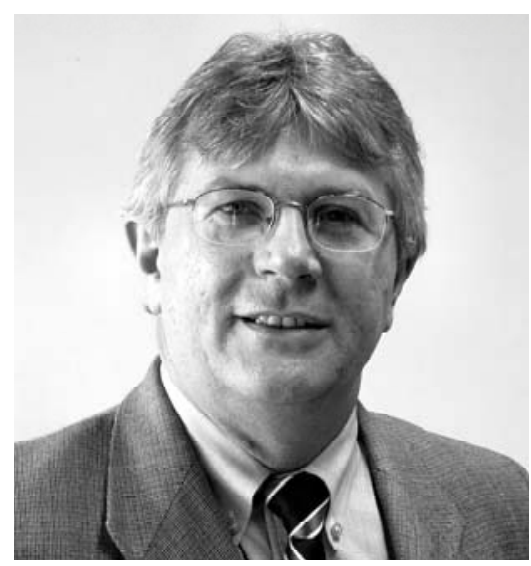

Professor Adjunto, Departamento de Medicina Interna e Programa de PósGraduação em Ciências Médicas: Endocrinologia; Diretor, Faculdade de Medicina, Universidade Federal do Rio Grande do Sul (UFRGS). Chefe da Unidade de Neuroendocrinologia, Serviço de Endocrinologia, Hospital de Clínicas de Porto Alegre, UFRGS.

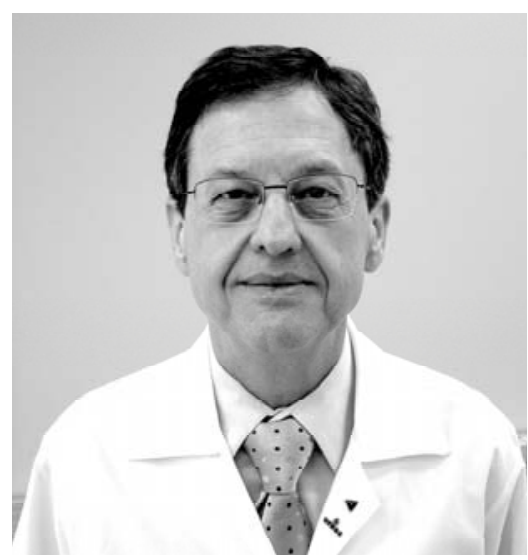

Professor Titular, Departamento de Medicina Interna e Programa de PósGraduação em Ciências Médicas: Endocrinologia, Faculdade de Medicina, Universidade Federal do Rio Grande do Sul (UFRGS). Chefe do Serviço de Endocrinologia, Hospital de Clínicas de Porto Alegre, UFRGS. 
ciadas às neoplasias. A idéia ganhou apoio imediato dos Editores dos Arquivos e foi por nós assumida como um grande desafio. Diferentemente das Edições Especiais anteriores, que congregavam uma área de conhecimento consolidada na endocrinologia, necessitávamos organizá-la. Assim, após alguma reflexão, optamos por abordá-la a partir das neoplasias mais prevalentes e dos principais distúrbios endócrinos decorrentes do câncer e/ou de seu tratamento, incluindo neoplasias benignas mais freqüentes. Procuramos buscar colaboradores com produção científica e experiência nos temas, obtendo-se ao final um resultado que consideramos muito expressivo, uma vez que o volume está sendo editado com 26 artigos, envolvendo um grupo significativo de autores nacionais e internacionais. Além destes, certamente muitos outros colegas poderiam também ter sido convidados. Outros temas poderiam ser incluídos. Enfim, temos a noção de que estamos trabalhando com uma visão nova de nossa especialidade e, por certo, podemos ter omitido temas e pessoas importantes.

Esta Edição Especial contempla artigos abordando diversos aspectos dos tumores das glândulas endócrinas, desde os mecanismos patogênicos e moleculares até as manifestações clínicas e abordagens terapêuticas. De uma maneira geral, todas as glândulas foram abordadas, assim como se discutiu o papel dos hormônios no desenvolvimento das neoplasias, algu- mas manifestações endócrinas das neoplasias, como também as repercussões da radioterapia no sistema endócrino. Com este amplo conjunto de artigos e abordagens esperamos oferecer aos leitores dos ABE\&M uma atualização que contribua para o dia-adia do endocrinologista clínico e desperte ainda mais a curiosidade científica de nossos pesquisadores.

Finalizando, gostaríamos de agradecer a importante colaboração dos autores que aceitaram nosso desafio e produziram os artigos que aqui apresentamos, e ao nosso dedicado e competente Editor-Chefe, Dr. Claudio Kater, que apoiou nossa iniciativa e muito contribuiu para torná-la realidade. Estamos certos de que esta Edição Especial será de muita utilidade para a comunidade dos endocrinologistas brasileiros, consolidando seu papel no entendimento e na assistência dos pacientes com tumores endocrinológicos.

\section{Endereço para correspondência:}

Mauro Antonio Czepielewski

Serviço de Endocrinologia / Departamento de Medicina Interna

Hospital de Clínicas de Porto Alegre - HCPA

Faculdade de Medicina, Universidade Federal do Rio Grande do Sul

Rua Ramiro Barcelos 2400, 4 andar

90035-003 Porto Alegre, RS 